\title{
Effect of Butadiene in Catalytic Trimerization of Isobutene Using Commercial $\mathrm{C}_{4}$ Feeds
}

\author{
Ji Woong Yoon, Sung Hwa Jhung,${ }^{\dagger *}$ Ji Sun Lee, Tae-Jin Kim, ${ }^{\ddagger}$ Hee-Du Lee, ${ }^{\ddagger}$ and Jong-San Chang \\ Research Center for Nanocatalysts, Korea Research Institute of Chenical Technologn, P.O. Box 107, Yustmg, \\ Daejeon 305-600, Korea. ${ }^{*}$ E-mail jschangakrict.re.kr \\ ${ }^{\dagger}$ Deparment of Chemistry, Kungpook National Lniversitu, Daegu 702-701, Korea. ${ }^{*}$ E-mail: sunga anu ac kr \\ -R\&D Center, SK Energy: Iuseong, Daejeon 305-712, Korea \\ Received October 1, 2007
}

\begin{abstract}
Catalytic oligomerization of isobutene to produce triisobutenes has been performed over a cation-exchange resin (Amberlyst-35) by using commercial $C_{4}$ feeds. The catalytic activity in the oligomerization was retained without deactivation up to $90 \mathrm{~h}$ of reaction in a simulated reaction feed without butadiene. but its activity was significantly affected by the presence of butadiene in commercial $C_{4}$ feeds. The isobutene conversion with time-on-stream was significantly decreased in the presence of butadiene. indicating the catalyst deactivation by butadiene. However the stable activity for trimerization was accomplished when the oligomerization was carried out after eliminating butadiene by hydrogenation of the feeds. This work demonstrates that butadiene play's a role as a cataly st poison on the solid acid cataly st. so that its removal in the reactant feed is essential for practical application of trimerization.
\end{abstract}

Key Words : Isobutene. Trimerization. Oligomerization. Butadiene. Cation-exchange resin

\section{Introduction}

In the petrochemical industry. $\mathrm{C}_{4}$ stream including butenes is an important raw material that can be upgraded. Recently. trimerization of light olefins has attracted considerable attention as a way of producing fuel additives ${ }^{l}$ and separating isoolefins from other olefins. 2 Particularly. triisobutenes are considered to be highly useful for the sy'nthesis of specialty chemicals including neo-acids. ${ }^{2}$ Heavy alkylates containing $\mathrm{C}$ or higher carbons can be produced by the hydrogenation of olefin oligomers such as triisobutenes. They are used as additives for kerosene and jet fuel ${ }^{3}$ and as odorless premium solvents without aromatics.

The blending of MTBE (methyl-tert-butyl ether) in gasoline has been banned in California ${ }^{4}$ since 2004 because it can give rise to environmental pollution due to the dissolution of MTBE in underground water. Isobutene is one of the main raw materials for the synthesis of MTBE. Therefore. the surplus of isobutene will take place in petrochemical industry if the regulation to prohibit the blending of MTBE will be also dominated in other countries. The trimerization of isobutene is a promising reaction for the production of isobutene trimers and heavy alky lates as a new way to utilize surplus isobutene. Despite the importance of the utilization of isobutene. the trimerization has not received so much attention so far in comparison with the dimerization of olefins. ${ }^{5-10}$ Several solid acid catalysts such as sulfated titania. ${ }^{1.11 .12}$ cation exchange resins (CERs) ${ }^{2.13}$ heteropoly acid ${ }^{14}$ zirconia $^{15}$ and zeolites ${ }^{16.17}$ have been suggested for the trimerization. Recently, we have reported the isobutene trimerization over solid acid catalysts such as zeolites beta (BEA) ${ }^{16}$ and ferrierite (FER) ${ }^{17}$ and cationexchange resins (Amberly'st-35 and Amberlyst-15) ${ }^{13.18}$ Iso- butene is usually exists in the $\mathrm{C}_{4}$ feed stream of a chemical plant. However in most cases. the trimerization has been mainly conducted using simulated feeds consisting isobutene diluted with paraffin solvents such as iso-butane and $n$ butane. etc. The oligomerization of isobutene using commercial $C_{4}$ feeds is. therefore. necessary for practical application.

In this work, we conducted the trimerization reaction over a cation-exchange resin catalyst by using commercial feeds containing isobutene in order to understand the effect of feed compositions on the oligomerization of isobutene. Especially. we focused on the effect of butadiene in the reaction.

\section{Experimental}

Oligomerization reaction was carried out in the liquidphase using a fixed bed continuous flow reactor (OD l inch. stainless steel 316) equipped with a back pressure regulator (Tescom). The reaction temperature and pressure of the reaction were $70^{\circ} \mathrm{C}$ and 15 bar. respectively. The reactor temperature was maintained constant by a water jacket in which water. kept at constant temperature. was flowing continuously with the help of a circulator.

Three different feeds were used in the oligonerization reaction. One is a simulated feed made by mixing isobutene ( $99 \%$. Rigas Korea) and n-butane (99\%. Rigas Korea) and called SIM ( $50 \mathrm{wt} / 50 \mathrm{wt}$ isobutene $/ n$-butane). Two conmercial feeds containing different concentration of butadiene. obtained from $\mathrm{C}_{4}$ streams of steam-cracking units of SK Energy (Korea), were also used in the study without any treatment. The two feeds are named as NEP and NCC depending on the type of plant and the content of butadiene. The detail compositions of each reactant are summarized in Table 1 . 
Table 1. Compositions of the feeds used in this work ${ }^{a}$

\begin{tabular}{lccccccc}
\hline \multicolumn{1}{c}{ Feed $^{b}$} & i-butene & in-butane & 1,3 -butadiene & 1-butene & i-butane & trans-2-butenle & cis-2-butene \\
\hline SIM & 50.00 & 50.00 & 0.00 & 0.00 & 0.00 & 0.00 & 0.00 \\
NEP & 49.09 & 6.36 & 0.22 & 28.73 & 1.11 & 9.57 & 4.92 \\
NEP (after hydrogenation) & 47.56 & 7.79 & $<0.01$ & 26.87 & 1.57 & 10.52 & 5.69 \\
NCC & 56.07 & 5.95 & 0.67 & 23.08 & 2.04 & 8.64 & 3.55 \\
NCC (after hydrogenation) & 54.53 & 9.30 & $<0.01$ & 20.44 & 1.93 & 8.94 & 4.86 \\
\hline
\end{tabular}

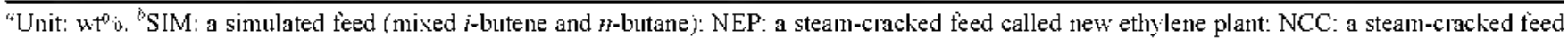
called naphtha cracking center

The reactant containing isobutene was continuously fed by using liquid mass flow controllers (Bronkhorst HI-TEC). The space velocity of isobutene. WHSV (weight-hourly space velocity. g-isobutene/g-dried catalyst/h) was varied between $5 \cdot 10 \mathrm{~h}^{-1}$ by controlling the flow rates of isobutene. $n$-butane or NEP and NCC feeds. The conversion of isobutene was determined by analyzing frequently the composition of the off-gas stream by using a GC equipped with a TCD and an alumina column (J\&W Scientific. $30 \mathrm{~m} \times 0.53$ $\mathrm{mm})$. Liquid products were analyzed by a FID GC containing a PONA colunn (HP. $50 \mathrm{~m} \times 0.20 \mathrm{~mm}$ ). In this study. the selectivity for dimers. trimers and tetramers is described in wt $\%$.

A cation exchange resin, called Amberlyst-35. macroporous and containing sulphonic acids. was purchased from Rohm and Haas. The acid capacity of the resin is $5.2 \mathrm{H}^{+} / \mathrm{g}$. and the catalysts were used without further purification. The extra water $(-50 \mathrm{wt} \%)$ that remained in the cation exchange resin was not removed or replaced because water-containing cation exchange resins show good performance ${ }^{13}$ Catalysts (2.5.5 $\mathrm{g}$ on dry base. together with five times of quartz beads for dilution) were loaded in the reactor as beads.

The hydrogenation of feed to eliminate the butadiene was conducted similar to the reported method. ${ }^{5}$ The conmercial NEP and NCC feeds were hydrogenated continuously at 50 ${ }^{\circ} \mathrm{C}$ in the presence of $\mathrm{Pd}(5 \%) / \mathrm{C}$ cataly st $(0.83 \mathrm{~g})$. The molar ratio of hydrogen/butadiene was 10 and the WHSV (g-feed/ g-dried catalysth $/$ ) of the feeds was $30 \mathrm{~h}^{-1}$. The flow rates of hy'drogen and butadiene were $3.7 \mathrm{cc} / \mathrm{min}$ and $0.0055 \mathrm{~g} / \mathrm{h}$. respectively for NEP feed. After the hydrogenation. the butadiene contents of NEP and NCC feeds were below the detection limit of the FID GC.

In order to recover the catalytic activity after deactivation. the aged catalysts showing the conversion of $83.5 \pm 1.5 \%$ were washed by flowing n-butane at $70^{\circ} \mathrm{C}$ for $10 \mathrm{~h}$. The flow rate of $n$-butane was $25 \mathrm{~g} / \mathrm{h}$. After the activation. the remained $n$-butane was replaced with the feed containing isobutene for oligomerization reaction.

\section{Results and Discussion}

Figure 1 shows the isobutene conversion and trimers selectivity depending on the time-on-stream to compare the effect of feed composition. As the feed contains the higher concentration of butadiene. the conversion decreases more rapidly with time-on-stream. Considering the space velocity.

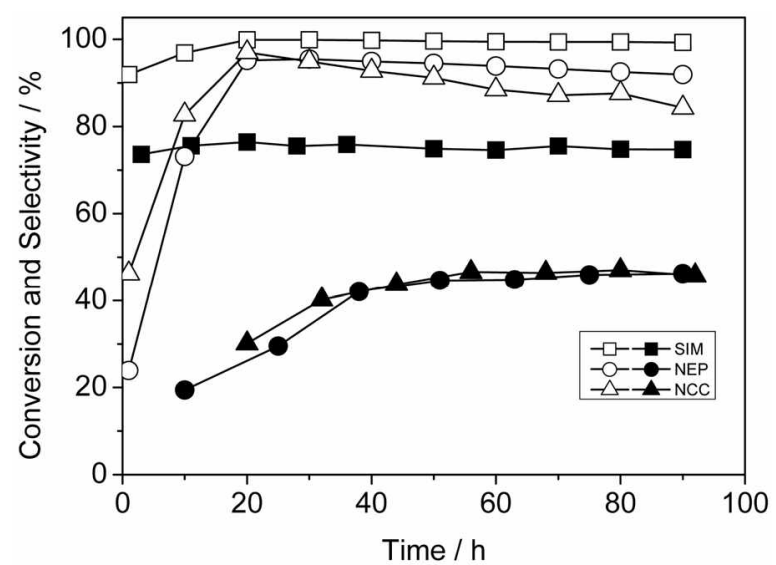

Figure 1. The isobutene conversion (empty symbols) and trimers selectivity (filled symbols) depending on the feed and time-onstream. The WHSV values for SIM, NEP and NCC are 10,5 and 5 $h^{-1}$, respectively.

the catalyst is very stable for the simulated feed with a mixture of isobutene and $n$-butane without butadiene because the space velocity is two times higher than the space velocity of the reactions using NEP and NCC feeds. It has been reported that the catalyst lifetime decreases very rapidly with increasing the space velocity ${ }^{13.16-18}$ The increase of conversion up to $20 \mathrm{~h}$ is due to the repalcement of water. the solvent which exists in the cation exchange resin. with reactants such as isobutene and $n$-butane ${ }^{13}$

The effect of diolefin such as butadiene has been reported in a few acid-catalyzed reactions such as isomerization ${ }^{\text {?II }}$ and dimerization of $n$-butenes. ${ }^{5,21}$ Butadiene led to a decrease of the catalyst lifetime in both isomerization and dimerization due to complexing an active site $(\mathrm{Ni})$ or pore blocking. Similarly, the negative effect of butadiene is also observed in the isobutene trimerization in this study. The deactivation by butadiene may be ascribed to masking of the acid sites because the pore size is very wide (macroporous resin) and there is no metal sites in the Amberlyst-35 catalyst. The partial masking of butadiene onto catalytically active sites seems to be very strong so that the activity is not fully recovered or the deactivation rate is high for the re-activated catalyst even though a large part of the catalytic activity can be recovered by washing with $n$-butane (see below)

Curiously, the trimers concentrations are very low for the products obtained from NEP or NCC feed compared with the case of trimerization from SIM feed even though the 


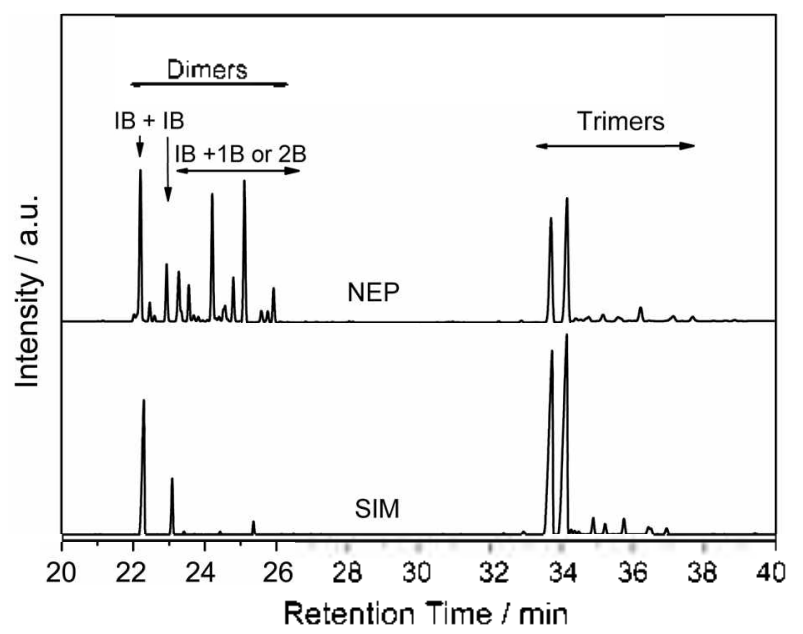

Figure 2. Gas chromatograms in the regions for dimers and trimers (time-on-stream: $100 \mathrm{~h}$ ) obtained by the oligomerization of SIM and NEP feeds. IB, IB and 2B represent isobutene, l-butene and 2butene, respectively.

isobutene concentration is about $50 \%$ for three feeds (Figure 1). It has been reported that codimerization reactions between isobutene and $n$-butenes are slower than isobutene dimerization ${ }^{15}$ in the etherification/dimerization of isobutene. Even though the codimerization is slow reaction, the codjmers are obtained noticeably probably because of low activity of codimers for trimerization or high concentration of $n$-butenes suitable for codimerization. The reactivity of codimers for trimers is less than that of isobutene dimers (see below).

Figure 2 shows the typical GC chromatogranis in the region of dimers and trimers obtained from SIM and NEP feeds. The concentration of codimers made from isobutene and n-butenes is very high in the case of codimerization from NEP, whereas the cluontatograms in the region of trimers do not show noticeable difference between the trimers from SIM and NEP feeds. This might be the fact that the reaction rate between dimers and $n$-butenes will be lower than that between dimers and isobutene. The reaction

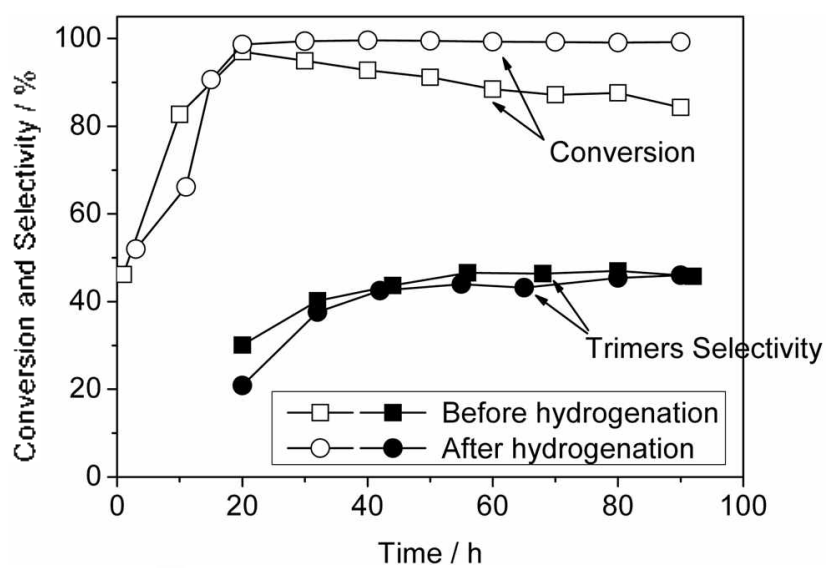

Figure 3. Effect of hydrogenation of NCC feed on the isobutene conversion and trimers selectivity: The WHSV and temperature were $5 \mathrm{~h}^{-1}$ and $70^{\circ} \mathrm{C}$, respectively.

between dimers and $n$-butene has an intermediate composed of secondary carbocation, whereas the intermedate made from dimers and isobutene will be tertiary carbocation. Therefore. the trimers are relatively easily produced from the addition of isobutene to dimers. Considering the low triisobutene and high codimers from NEP feed. it may be assumed that the codimers are less active for isobutene addition.

Before the reaction, the commercial feeds are hydrogentated by using hydrogen in the presence of $\mathrm{Pd} / \mathrm{C}$. and the hydrogenated feeds were applied in the oligomerization reactions to confirm the effect of butadiene. As shown in Figure 3, the stability is noticeably improved after hydrogenation of the NCC feed. The stable production of isobutene trimers are also observed after $20 \mathrm{~h}$ from the hydrogenated NCC feed (Figure 4a). Very similarly, the NEP feed can also be oligonerized stably from $30 \mathrm{~h}$ to $90 \mathrm{~h}$ after hydrogenation of the feed (Figure 4b). The increase of isobutene conversion before $20-30 \mathrm{~h}$ is due to the replacement of water by feeds. ${ }^{13}$

Facile regeneration of an aged catalyst is very important
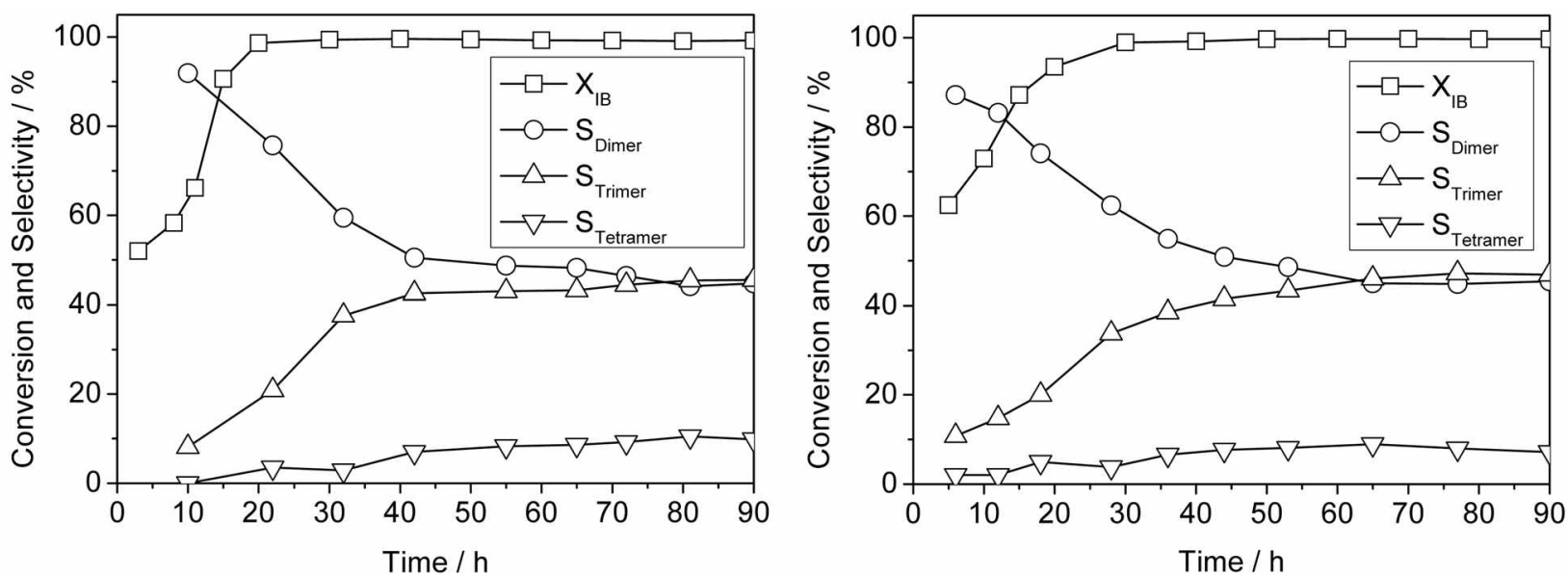

Figure 4. The isobutene conversion and selectivities for dimers, trimers and tetramers after the hydrogenation of NCC feed (left) and NEP teed (right). The WHSV and temperature were $5 \mathrm{~h}^{-1}$ and $70^{\circ} \mathrm{C}$, respectively. 


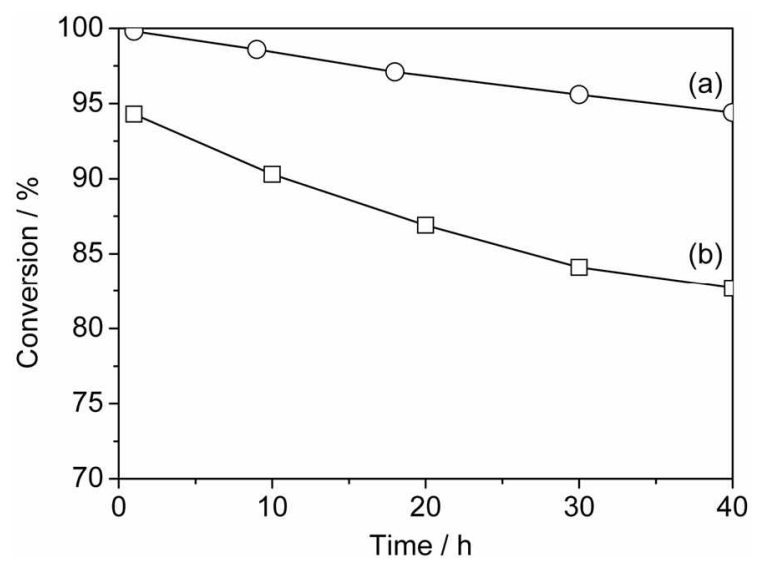

Figure 5. Effect of hydrogenation of the NEP feed on the recovery of the activity and deactivation rate after activation: (a) with hydrogenation: (b) without hydrogenation. The WHSV and temperature were $5 \mathrm{~h}^{-1}$ and $70^{\circ} \mathrm{C}$, respectively.

for commercial applications. The aged catalysts were activated by washing with n-butane for $10 \mathrm{~h}$. The catalyst aged by hydrogenated feed recovers the activity to the conversion of $100 \%$. However. the conversion was about $95 \%$ even after the regeneration (washing with $n$-butane) of the aged (by non-hydrogenated feed) catalyst (Figure 5). These facts show that the deactivated catalyst aged by hydrogeanted feed restores the activity more easily than the deactivated catalyst used for the oligomerization for the non-hydrogenated feed. Moreover. the re-activated catalyst that was aged by non-hydrogenated feed loses activity more rapidly compared with the re-activated catalyst after the deactivating with hydrogenated feed (Figure 5). However, the re-activated catalysts. even after the catalyst was deactivated by hydrogenated feed. lose activity rapidly compared with a fresh catalyst. suggesting the washing does not fully recover the performance (especially stability) for the oligomerization.

\section{Conclusion}

The oligomerization of isobutene has been investigated for commercial $\mathrm{C}_{4}$ feeds containing wide concentrations of butadiene. Butadiene has been found to decrease the activity rapidly probably because of poisoning the acid sites of the cation-exchange resin. The deactivation by butadiene can be diminished by hydrogenation of the feeds before the oligomerization. It is also found that the deactivated cataly st aged by non-liydrogenated feed is less efficient in recovering the activity by washing with $n$-butane. The catalyst. previously deactivated by oligomerization of non-hydrogenated feed. does not fully restore the activity even by re-activation through the washing. and the second deactivation rate is high compared with the catalyst aged by hydrogenated feed.

Acknowledgement. This work was supported by the Korea Ministry of Commerce, Industry and Energy (TS07503).

\section{References}

1. Mantilla, A.; Ferrat, G.; Lopez-Ortega. A.: Romero. E.: Tzompantzi, F.: Torres. M.: Ortiz-Islas. E.: Gomez. R. J. Mol. Catal A 2005. 228.333 .

2. Alcantara. R.: Alcantara. E.: Canoira. L.: Franco. M. T.: Herrera. M. Navarto, A. Reactive Funct. Polymer 2000, +5, 19.

3. wwwaxens net

4. Burnes, E.; Wichelns, D; Hagen, J. W. Energy Policy 2005, 33. 1155.

5. Jeon1. T.-K.: Park. S.-K.: Park. Y.-K. Catal. Todav 2004. 93-95. 467.

6. Honkela, M. L.; Krause, A. O. Ind. Eng. Chem. Res. 2004. 43. 3251 .

7. Marchionna, M:- Girolamo. M. D.: Patrini, R. Catal. Today 2001. 65. 397.

8. Girolamo. M. D.: Marchionna. M. J. Mol Catal. A 2001. 177. 33.

9. Chiche. B.: Sauvage. E.: Renzo. F. D.: Ivanova. I. I.: Fajula. F. J. Mol. Catal A 1998. J34. 145.

10. Girolamo, M. D: Lam, M.; Marchionna, M.: Percarollo, E:; Tagliabue L; Ancillotti. F. Ind Eng. Chem. Res. 1997. 36. 4152.

11. Mantilla. A.; Tzompantzi. F.: Ferrat G.: Lopez-Ortega, A.: Romero, E.: Ortiz-Islas. E.: Gomez. R.: Torres. M. Chem. Commm. 2004. 1498.

12. Mantilla. A.: Tzompantzi. F.: Ferrat. G.: Lopez-Ortega. A.: Alfaro. S.: Gomez, R.: Torres, M. Catal. Today 2005, 107-108. 707

13. Yoon. J. W: Chang, J.-S.; Lee, H.-D.: Kim, T.-J; Jhung, S. H. $d$. 1 fol Catal A 2006, 260, 181.

14. Japanese Patent JP 2005015383 (assigned to Idemitsu Kosan).

15. Japanese Patent JP 2005015384 (assigned to Idemitsu Kosan).

16. Yoon1. J. W.: Chang. T.-S.: Lee. H.-D.: Kim. T.-J.: Jhung. S. H. J. Catal. $2007,2+5.253$.

17. Yoon. J. W; Lee, J. H; Chang, J.-S.: Choo, D. H.; Lee, S. J.; Jhung. S. H. Catal. Conmum 2007, 8,967.

18. Yoon. J. W.: Jhung. S. H.: Kimn. T.-J.: Lee. H.-D.: Chang. J-S. Bull. Kor. Chem. Soc. 2007. 28. 2075.

19. Acid capacity of the CER is obtained from wwwrhomandhaas. comionexchange IPisac.htm.

20. Pingruber, G. D.; Seshan. K; Lercher. J. A. Mficroporous Hesoporous Hater: 2000. 38. 221

21. Podrebarac. G. G.: Ng. F. T. T.: Rempel. G. L. Appl. Catal A 1996. 1+7. 159. 